\title{
Dermoscopy of Congenital Langerhans Cell Histiocytosis
}

\author{
Ramon Pigem, ${ }^{1}$ Ariann Dyer, ${ }^{1}$ Sebastian Podlipnik, ${ }^{1}$ Cristina Carrera, ${ }^{1}$ \\ Susana Puig, ${ }^{1}$ Juan Ferrando ${ }^{1}$
}

1 Department of Dermatology, Hospital Clínic, Universitat de Barcelona, Barcelona, Spain

Key words: Langerhans cell, histiocytosis, solar eclipse, dermoscopy

Citation: Pigem R, Dyer A, Podlipnik S, Carrera C, Puig S, Ferrando J. Dermoscopy of congenital Langerhans cell histiocytosis. Dermatol Pract Concept. 2020;10(3):e2020063. DOI: https://doi.org/10.5826/dpc.1003a63

Accepted: March 28, 2020; Published: June 29, 2020

Copyright: $@ 2020$ Pigem et al. This is an open-access article distributed under the terms of the Creative Commons Attribution License, which permits unrestricted use, distribution, and reproduction in any medium, provided the original author and source are credited.

Funding: None.

Competing interests: The authors have no conflicts of interest to disclose.

Authorship: All authors have contributed significantly to this publication.

Corresponding author: Ramon Pigem, MD, Department of Dermatology, Hospital Clínic of Barcelona, Villarroel, 170 (08036) Barcelona, Spain.Email: RPIGEM@clinic.cat

\section{Introduction}

Langerhans cell histiocytosis ( $\mathrm{LCH})$ is a dysfunction and proliferation of Langerhans cells that cause a polymorphic disease depending on the affected organs [1]. We present the dermoscopic appearance of congenital LCH.

\section{Case Presentation}

A healthy-appearing preterm newborn presented with multiple erythematous and violaceous maculopapular and nodular skin lesions scattered over trunk, face, scalp, nails, palms, and soles. The lesions were purplish-brownish, elastic, and not ulcerated. No other abnormalities were found.

The lesions presented with variable clinical and dermoscopic appearance depending on the stage. The most striking finding was the presence of reddish lilac pigmentation of nodular lesions with the presence of peripheral violaceous vessels resembling a solar eclipse (Figure 1). The majority of small papules showed multiple violaceous lacunae and clods over a light brown background; others presented a central scar-like area surrounded by whitish streaks (Figure 2).

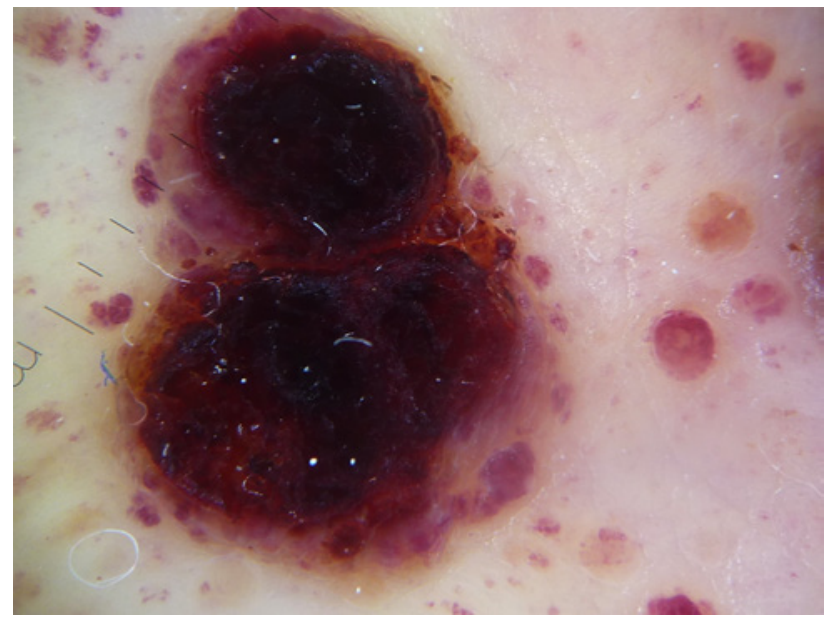

Figure 1. Dermoscopic examination of a lesion in the fully developed stage. The dark pigmentation in the center and the violaceous vessels on the periphery resemble a solar eclipse over a starry sky. Note the burgundy color of the vessels.

Histopathology confirmed the diagnosis of LCH, presenting diffuse proliferation of histiocytes in the reticular dermis surrounded by ectatic vessels (Figure 3). Immunohistochemical staining results for $\mathrm{S} 100, \mathrm{CD} 1 \mathrm{a}$, and langerin were 


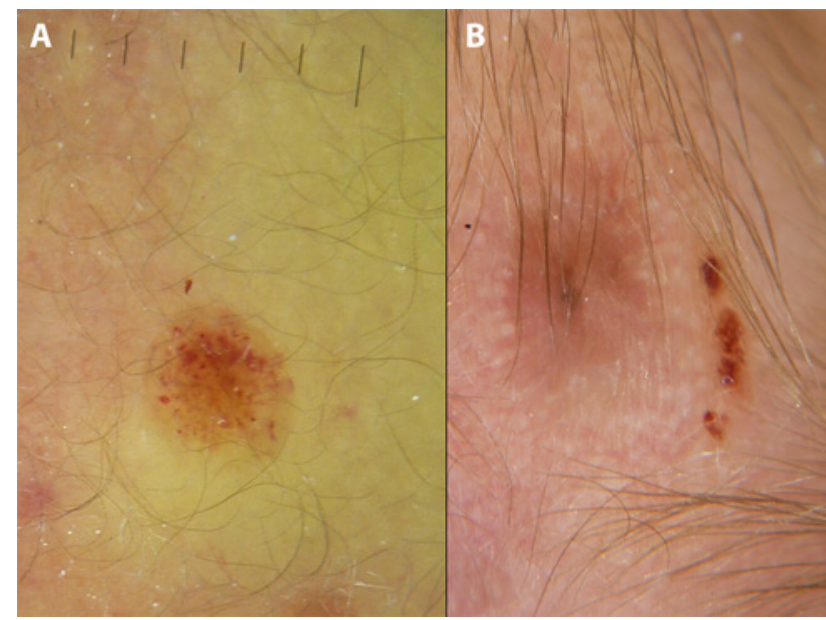

Figure 2. Dermoscopic examination of 2 different lesions. (A) Lesion in the early evolutionary stage with multiple violaceous lacunae and mild brown pigmentation. (B) Different lesion in the late regressive stage with central scar surrounded by whitish streaks and an eccentric focus of residual pigmentation.

positive. Electron microscopy showed large histiocytes with reniform nuclei and Birbeck and vermiform bodies (Figure 4).

\section{Conclusions}

Dermoscopically characteristic lilac pigmentation and multiple burgundy round lacunae on the periphery were seen in our case. Especially when the lesions are in the fully developed stage, the dermoscopic image resembles a solar eclipse. There could be a parallel between this sign and the "setting sun" appearance described in early evolutionary and fully developed stages of juvenile xanthogranuloma (non-Langerhans cell histiocytosis) [2].

\section{References}

1. Shaffer MP, Walling HW, Stone MS. Langerhans cell histiocytosis presenting as blueberry muffin baby. J Am Acad Dermatol. 2005;53(2 Suppl 1):S143-S146. https://doi.org/10.1016/j. jaad.2005.01.015

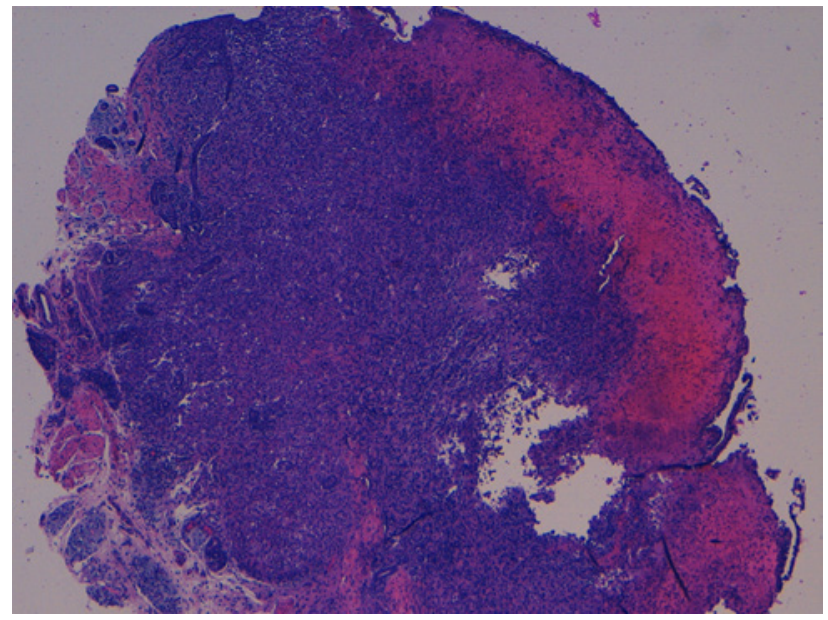

Figure 3. H\&E-stained biopsy showing a dense dermal infiltrate of large histiocytes with pale cytoplasm and ectatic vessels in the dermis. Original magnification $\times 40$.

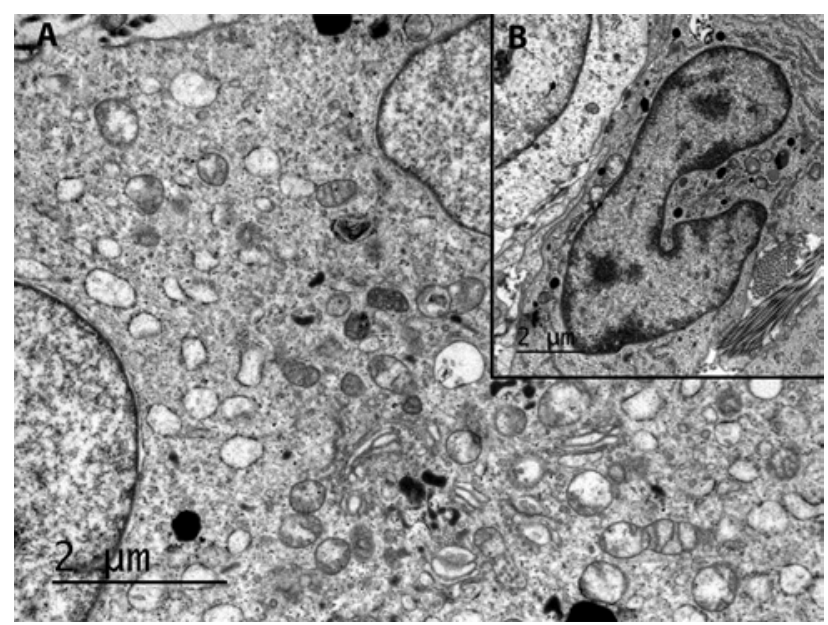

Figure 4. (A) Electron microscopy shows Birbeck and vermiform bodies. (B) Large histiocytes with reniform nuclei were also observed.

2. Song M, Kim SH, Jung DS, Ko HC, Kwon KS, Kim MB. Structural correlations between dermoscopic and histopathological features of juvenile xanthogranuloma. J Eur Acad Dermatol Venereol. 2011;25(3):259-263. https://doi.org/10.1111/j.14683083.2010.03819.x 